\title{
Elaboration and Physico-Mechanical Characterization of a New Eco-Mortar Composite Based on Magnetized Water and Fly Ash
}

\author{
Redouane Mghaiouini 1,2* Graich Abderrazzak², Nisrine Benzbiria³, \\ Anis Elaoud ${ }^{4}$, Toufik Garmim², Mohamed E. Belghiti ${ }^{5}$, \\ Mahmoud Hozayn ${ }^{6}$, Mohamade Monkade ${ }^{2}$, Abdeslam El Bouari ${ }^{1}$ \\ 1 Department of Chemistry, Physical Chemistry Laboratory Applied Materials, Faculty of Sciences-Ben M'sik, \\ Hassan II University, Casablanca, Morocco \\ 2 Department of Physic condensed Matter Laboratory, Faculty of Sciences, ChouaibDoukkali University, El \\ Jadida, Morocco \\ 3 Department of Chemistry, Laboratory of Interface Materials Environment, Faculty of Sciences-Aïn Chock, \\ Hassan II University, Casablanca, Morocco \\ 4 University of Carthage, Laboratory of Environmental Sciences and Technologies, Higher Institute of Scences \\ and Technology of Environment, Tunisia \\ 5 Laboratory of Nernest Technology, 163 Willington Street, Sherbrook, J1H5C Quebec, Canada \\ 6 Agronomy Dept., Agric. and Biol. Div., National Research Centre, El-Bohoth St., 12622 Dokki, Cairo, Egypt \\ * Corresponding author's e-mail: Filagri1.maroc@gmail.com
}

\begin{abstract}
This study examines the flexural strength and compressive strength of the mortars, which were mixed with the electromagnetic field treated water (EMFTW) and contained fly ash. EMFTW was obtained by passing the tap water through an electromagnetic field. The test variable was the fly ash content in place of cement and the water treated with EMFTW in place of the tap water. The results show that the flexural and compressive strength of the mortar samples mixed with MFTW is $12.56 \%$ and $15.8 \%$ higher than that prepared with the tap water, respectively. It was also found that the magnetized water improves the resistance to bending and compression by $12.67 \%$ and $4.35 \%$ to that prepared with the tap water and $10 \%$ fly ash instead of cement.
\end{abstract}

Keywords: water treated by electromagnetic field, Fly ash, compressive strength, bending strength, composite Mortar, XRD, and SEM.

\section{INTRODUCTION}

The need for water becomes more important with the growth of the number of inhabitants in the world. The industrial sector is in second place with a demand for water of $20 \%$ after the agricultural agriculture sector, which represents $70 \%$ of the water requirement [United Nations et al. 2016].

More than a billion tons of water is used annually in the real manufacturing sectors [Pang et al.2013]. The water used in the preparation of concrete plays a capital function in the formulation of concrete, starting with the organization of the hydration procedure of the cement, during the development and taking into account drying to arrive at the desired resistance, without neglecting the maneuverability and solidity of the concrete texture.

The application of the magnetized water reveals an encouraging possibility in order to optimize the supply of water introduced into concrete habitats [Pang et al.2013, Pradnya et al.2016]. The water crossed by an electromagnetic emission called electro-magnetized water. The degree of magnetization is regulated by the technique applied and by the clarity of the water [Pang 
et al.2013, Pradnya et al. 2016, Siva Konda et al.2013]. The texture of the water is arranged in one direction after processing, and the shape of the molecule differs depending on the variation in angle of the junction; thus, the surface tension and viscosity lower by magnetization; hence, the increase in the percentage of hydration [Pradnya et al.2016, Afshin et al.2010]. [Juan et al.2015] dealt with the influence of a magnetic flux on water and the authors argued that the hydrogen bonds $p$ resulted in better evolution due to the breaking of hydrogen bonds after the magnetization process.

Because of the small size of the magnetized water molecules, the water film flowing the cement is smaller than the non-magnetized water molecules; hence, lower water control which has an advantageous action on the mechanical properties of mortars.

For this original research, the samples were prepared with the magnetized water, which enables a better hydration of cement since water clusters are smaller favoring penetration into cement grain. Thus, the retention time was higher and the hydration was increased in comparison with the samples treated with tap water [Juan et al.2015]. The characteristics of fresh concrete were checked and confirmed by the magnetization of water [Afshin et al.2010]. Its result is did not change by the addition of fly ash as cement with various proportions starting up to $25 \%$, while the water / cement fraction remains fixed [Nan et al. 2003]. The indicators of durability and the shortening of the drying of concrete mixing with magnetized water were improved compared to the concrete with untreated water [Manjupriya et al. 2016], in addition, the research on the action of MFTW on the mortars containing ash flying were also abundant. It is obvious that the fly ash is pozzolana. The mortar made from fly ash contributes to pollution control through good management of waste from thermal power plants and improves the technical characteristics such as long-term bending and compressive strength [Mehta et al. 1986 ]. Magnetized water can retain its magnetization for up to seven days (memory effect) [Mghaiouini et al.2020]. Magnetized water improves the germination of lettuce (Lactuca sativa L.) [Mghaiouini et al.2020]. This research analyzed the compressive and flexural strength of the cement mortar prepared with MFTW after 28 days of storage in air. Additionally, the action of MFTW on the microscopic structure of the mortar manufactured with fly ash replacing a fraction of the cement was analyzed as well.

\section{MATERIALS AND METHODS}

\section{Mortar preparation}

Mortar is a composite material, essentially consisting of a mixture of three ingredients: sand, hydraulic binder (cement or lime) and water, which is generally the tap water. In this study, fly ash (FA) is valued in the cement mortar by replacing it with different percentages of FA with FA / cement mass ratios equal to: $10 \%$. In order to determine the mechanical properties, the mortars are prepared according to the European standard NF EN 196-1 which requires that the normal mortar be composed in mass, of a portion of cement $(450 \mathrm{~g})$, three portions of sand $(1350 \mathrm{~g})$ and half a portion of water $(225 \mathrm{~g})$, i.e. with a water / cement ratio: $\mathrm{W} / \mathrm{C}=0.5$. The products were mixed for 4 minutes in accordance with the requirements of the standard in a $5 \mathrm{~L}$ mixer at ambient temperature and at a relative humidity higher than 50\% [Helmuth et al. 1987]. Before starting the mechanical study, the mortars were prepared in the form of prismatic test pieces with the dimensions $4 \times 4 \times 16 \mathrm{~cm}$ as shown in Figure 1 . The samples thus formed were stored in the open air, then these test pieces were tested after 28 days in terms of their mechanical bending and compression strength. Table 1 shows the complete formulation of the mortars. The B0 mortar is the normal mortar that was taken as a reference. The B10 mortar, was obtained by replacing part of the cement with fly ash 10 by mass.

\section{Characterization of the materials used}

The cement used in the preparation of mortars is CEM II (CPJ 45) defined in the Moroccan standard NM 10.1.004. It is a Portland cement made up of $81.5 \%$ clinker, $12 \%$ limestone, the rest is gypsum which regulates the setting. The chemical composition of CPJ 45 cement is presented in Table 2.

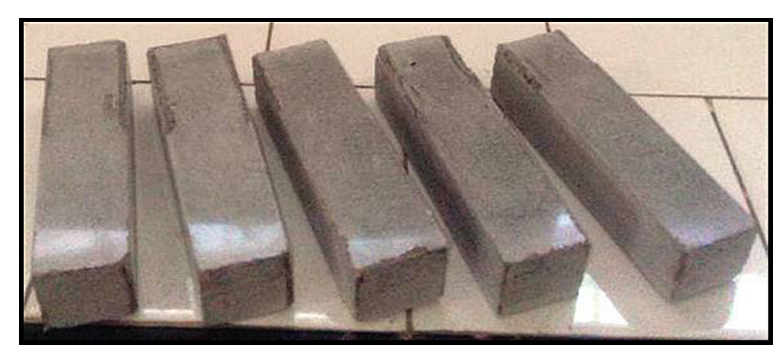

Figure 1. Mortar specimens 
Table 1. Formulation of mortars with $10 \%$ fly ash

\begin{tabular}{|c|c|c|c|c|}
\hline Element & Flay ach $(\mathrm{g})$ & Cement $(\mathrm{g})$ & Sand $(\mathrm{g})$ & Water $(\mathrm{g})$ \\
\hline B10 & 45 & 405 & 1350 & 225 \\
\hline
\end{tabular}

Table 2. Chemical composition of CPJ45 cement

\begin{tabular}{|c|c|c|c|c|c|c|c|}
\hline Cement & $\% \mathrm{SiO}_{2}$ & $\% \mathrm{Al}_{2} \mathrm{O}_{3}$ & $\% \mathrm{Fe}_{2} \mathrm{O}_{3}$ & $\% \mathrm{CaO}$ & $\% \mathrm{MgO}$ & $\% \mathrm{SO}_{3}$ & $\% \mathrm{~K}_{2} \mathrm{O}$ \\
\hline CPJ 45 & 17 & 5 & 3 & 63 & 2.3 & 3.33 & 1.2 \\
\hline
\end{tabular}

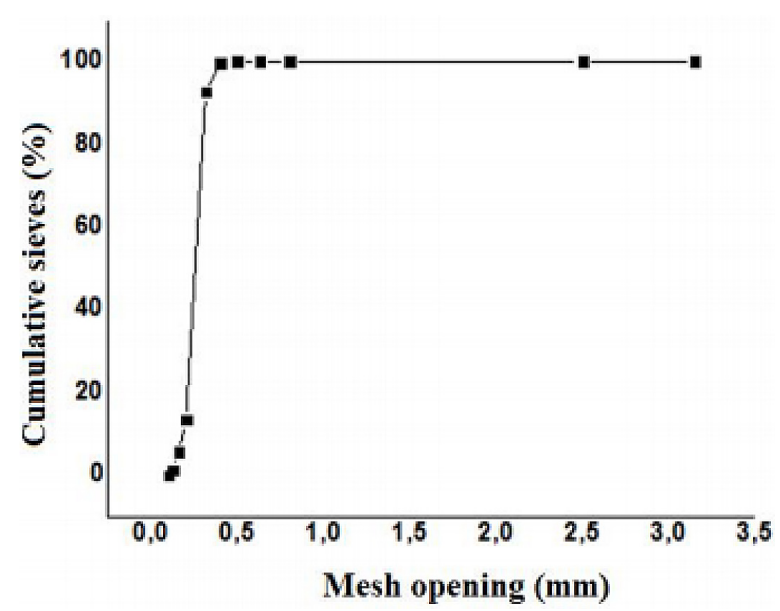

Figure 2. Particle size curve of the sand

The sand used in the mixtures was taken from the coast (Oualidia). Its particle size analysis was carried out according to the NF P18-560 standard [Zalaghi et al.2018] with an electric sieve shaker; the results obtained are summarized in the graph in Figure 2.

According to the grain size curve, the corresponding uniformity coefficient $\mathrm{Cu}$ is 1.7 and the predominant grain size is between $0.2 \mathrm{~mm}$ and $0.315 \mathrm{~mm}$. Therefore, the sand used is uniform and composed mainly of fine grains. The apparent density of the sand used was determined, considering a proportion of pores (voids) of $41.5 \%$ according to the reference [Fan et al. 2005]. The summarized results are presented in Table 3.

The actual density obtained, which is $2.77 \mathrm{~g} /$ $\mathrm{cm}^{3}$, corresponds well to the specific weight of fine sand, which generally varies around 2.65. Coal fly ash is a fine powder from the combustion of pulverized coal in the boilers of Jorf Lasfar "JLEC" thermal power plants. They are entrained by the flows of gaseous discharges generated by the combustion reaction and are thus captured by electrostatic filters which separate them from the gaseous discharges. The investigated fly ash samples are gray in color and have a smooth, shiny surface [Moufti et al. 2003]. They are fine and look like cement powder - see Figure 3.

The fly ash collected was obtained from the combustion of coal from South Africa. Each of the samples was obtained by quartering from several $5 \mathrm{~kg}$ samples. Quartering consists of dividing the sample into four equal parts. Two opposite parts are recovered and then homogenized. One of these last two parts is re-quartered and so on. The operation can be repeated three or four times

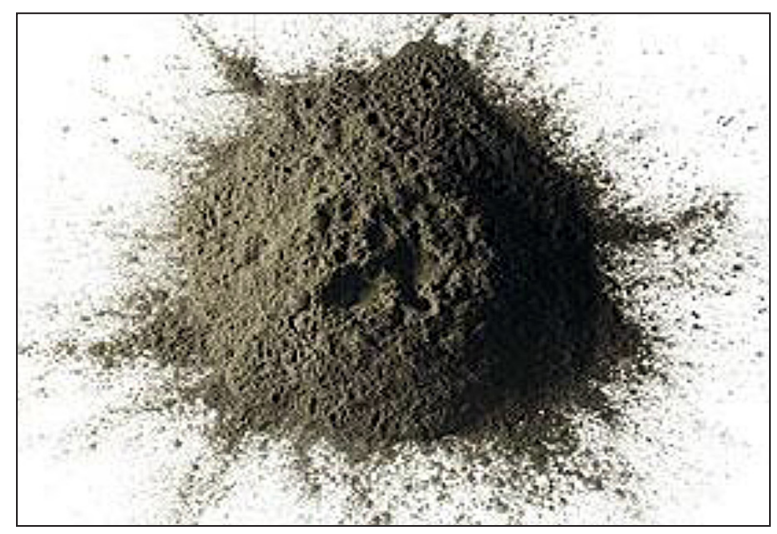

Figure 3. Visual appearance of fly ash

Table 3. Densities of the sand used

\begin{tabular}{|c|c|c|}
\hline Bulk density without compaction, $\mathrm{g} / \mathrm{cm}^{3}$ & Bulk density with compaction, $\mathrm{g} / \mathrm{cm}^{3}$ & Real density, $\mathrm{g} / \mathrm{cm}^{3}$ \\
\hline 1.43 & 1.54 & 2.77 \\
\hline
\end{tabular}

Table 4. Chemical compositions of fly ash obtained by ICP

\begin{tabular}{|c|c|c|c|c|c|c|c|}
\hline $\mathrm{SiO}_{2}$ & $\mathrm{Al}_{2} \mathrm{O}_{3}$ & $\mathrm{Fe}_{2} \mathrm{O}_{3}$ & $\sum \mathrm{SiO}_{2+} \mathrm{Al}_{2} \mathrm{O}_{3+} \mathrm{Fe}_{2} \mathrm{O}_{3}$ & $\mathrm{CaO}$ & $\mathrm{MgO}$ & $\mathrm{SO}_{3}$ & $\mathrm{~K}_{2} \mathrm{O}$ \\
\hline 57 & 34 & 3.4 & 94.4 & 5.05 & 0.02 & 0.5 & 0.03 \\
\hline
\end{tabular}


to obtain a representative sample [Adamiec et al. 2005]. Table 4 summarize the results of the chemical elements in the fly ash.

The chemical composition of the ash shows that the sum of the percentages of the elements: $\mathrm{SiO}_{2}, \mathrm{Al}_{2} \mathrm{O}_{3}$, and $\mathrm{Fe}_{z} \mathrm{O}_{3}$ is $94.4 \%$, which enables to classify them among the aluminous silica ash.

The mineralogical composition of fly ash is shown in Figure 4. Two peaks of mullite and quartz were detected in this experiment. During combustion, these minerals change their structure and give rise to a weak crystallized part in the form of mullite and quartz and an amorphous part [Zalaghi et al.2018]. This result agrees well with the mineralogical composition of bottom ash.

\section{Mechanical study}

The measurement of the mechanical bending strength of mortars was carried out on a material characterization machine provided with a three-point bending device, illustrated in Figure 5 [Graich et al.2020]. The experimental conditions used are described by the EN 196-1standard.The test piece is placed symmetrically on the ends of the support so that the direction of the force is perpendicular to the longitudinal axis of the test piece. A preload was applied to avoid any specimen play and to balance the displacement measurement device.

$$
R_{f}=\frac{3 F_{f} L}{2 b h^{2}}
$$

After bending, each half-prism was re-using to measure the compression strength - see Figure 6 [Graich et al. 2020].

A progressive force was on the cross section $(4 \times 4 \mathrm{~cm})$ of the test piece with the same speed until the breaking load from which the mechanical compressive strength can be calculated in megapascals using the formula:

$$
R_{c}=\frac{F_{c}}{b^{*} h}
$$

Afterwards, the samples were also analyzed by a Bruker diffractometer of flat technical form at the university of Chouaib Doukkali El Jadida Morocco, using a copper anticathode $(\mathrm{Cu}-\mathrm{K} \alpha)$ with wavelength $\lambda$ equal to $1.5406 \mathrm{~A}$. The samples after crushing were analyzed by a HITACHI $2500 \mathrm{C}$ scanning electron microscope.

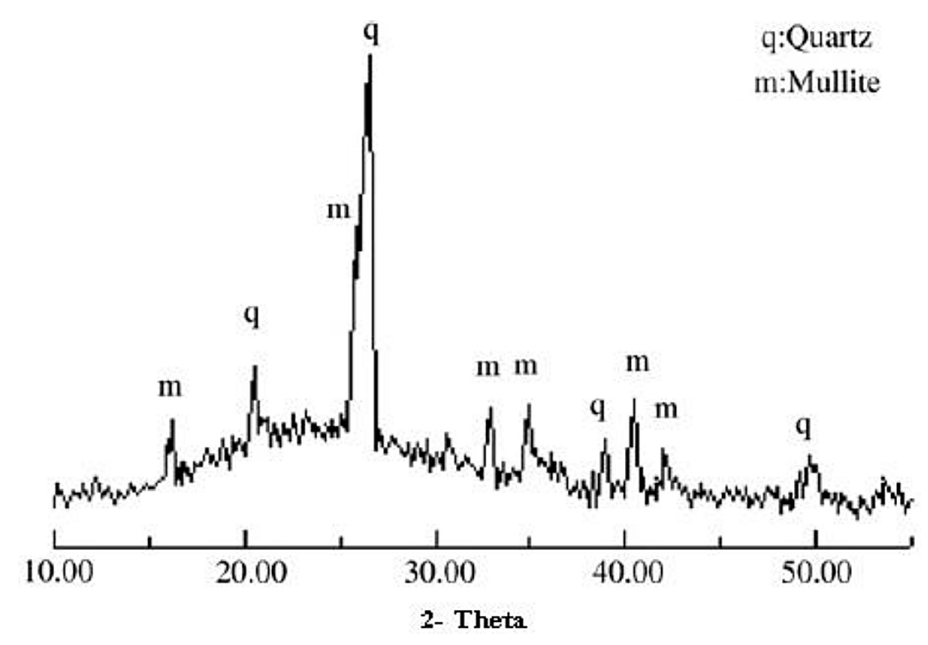

Figure 4. Mineralogical spectrum of the fly ash used
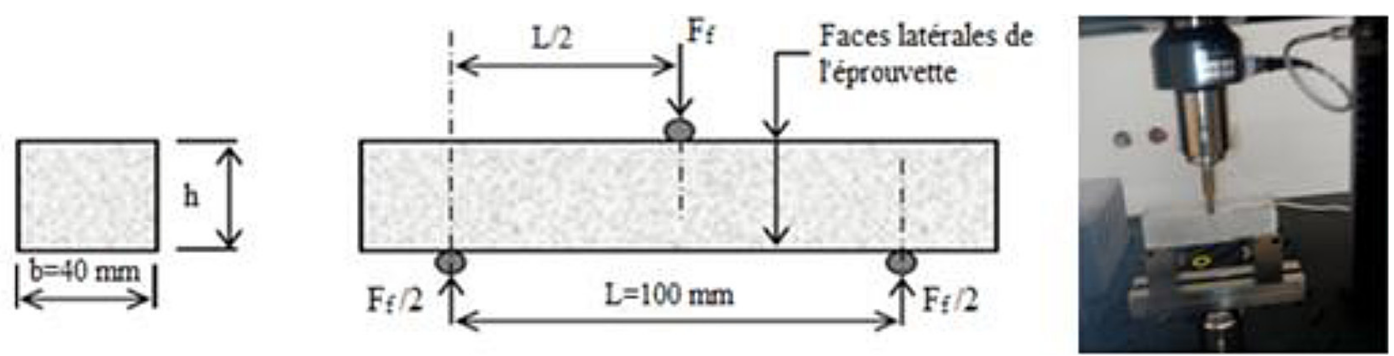

Figure 5. Mechanical bending strength test device 
Table 5. Physico-chemical analysis of tap water and magnetized water

\begin{tabular}{|c|c|c|}
\hline Settings & Tape water & Magnetic water \\
\hline $\mathrm{pH}$ & 7,69 & 8,25 \\
\hline Conductivity & $1695 \mu \mathrm{S} / \mathrm{Cm}$ & $471 \mu \mathrm{S} / \mathrm{Cm}$ \\
\hline TDS & $848 \mathrm{mg} / \mathrm{l}$ & $0,48 \mathrm{PSU}$ \\
\hline Conductivity & $0,85 \mathrm{PSU}$ & $79 \mathrm{mg} / \mathrm{l}$ \\
\hline Ca & $78.5 \mathrm{mg} / \mathrm{l}$ & $0.49 \mathrm{mg} / \mathrm{l}$ \\
\hline Oxydability & $0.41 \mathrm{mg} / \mathrm{l}$ & $89 \mathrm{mg} / \mathrm{l}$ \\
\hline Chloride & $88.5 \mathrm{mg} / \mathrm{l}$ & $17,8^{\circ} \mathrm{C}$ \\
\hline Temperature & $17,8^{\circ} \mathrm{C}$ & $23.9 \mathrm{mg} / \mathrm{l}$ \\
\hline Mg & $23.83 \mathrm{mg} / \mathrm{l}$ & $10.4^{\circ} \mathrm{F}$ \\
\hline Alkalinity & $10.35^{\circ} \mathrm{F}$ & $2.98 \mathrm{meq} / \mathrm{l}$ \\
\hline TH or title hydrometric & $2.94 \mathrm{meq} / \mathrm{l}$ & $0 \mathrm{mg} / \mathrm{l}$ \\
\hline Ammonium & $0 \mathrm{mg} / \mathrm{l}$ & $0 \mathrm{mg} / \mathrm{l}$ \\
\hline Fer & $0 \mathrm{mg} / \mathrm{l}$ & \\
\hline
\end{tabular}
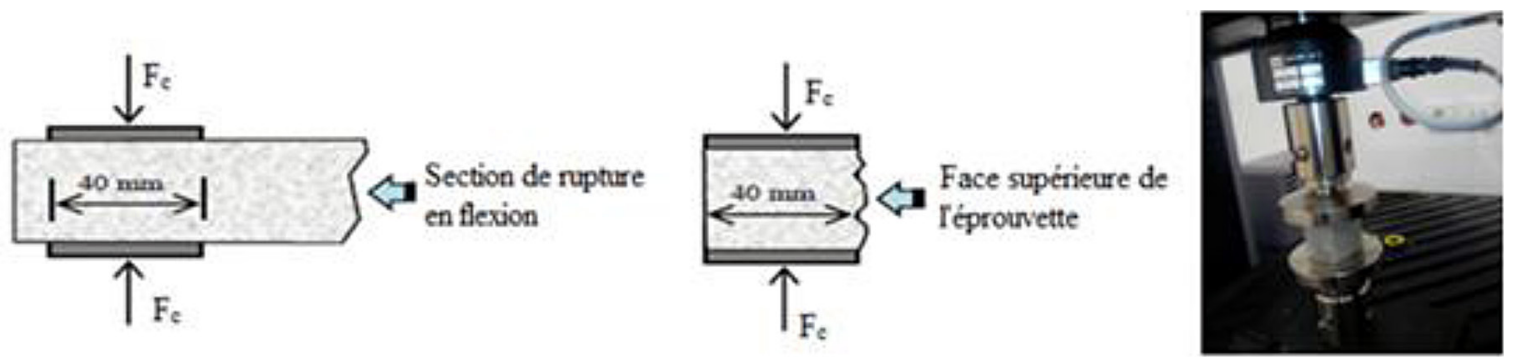

Figure 6. Compression mechanical resistance test device

\section{Experimental variables}

The tap water was treated through a similar electromagnetic field by electromagnetic device. Figure 7 shows the electromagnetic field generator machine developed for this research. The length of this machine is $804 \mathrm{~mm}$ and its weight is about $2 \mathrm{~kg}$. The diameter of the drain hose is $112 \mathrm{~mm}$. The water flow can be adjusted using a proportional integral differential regulator (PID). electromagnetic device system is a set composed of the following modules

- The F Pro command which brains the system. It generates the processing signals and continuously checks the proper functioning of the system.

- The processing units (TU) which diffuse the signals generated by the F Pro command into the water, as shown in Figure 7 . When the tap water passes through this electromagnetic field, it turns into EMFTW.

The authors prepared a cement based mortar to replace with $10 \%$ fly ash and a water / cement ratio $(\mathrm{W} / \mathrm{CM})$ equal to 0.5 .

\section{RESULTS AND DISCUSSION}

\section{Mechanical study of mortars}

Figures 8 and 9 show the flexural strength of the cured mortar samples for 28 days. Figures 10 and 11 show the relative compression strength of the 28-day mortar samples. Although prepared with varying percentages of substitution of cement with fly ash, all of the mortar samples show a similar trend, indicating that the effect of EMFTW magnetic field strength on compressive strength of different mortar samples is almost identical. As can be seen a percent fly ash is used instead of cement, the compressive and bending strength of the samples mixed with EMFTW are higher than those of the control (the tap water being represented by 0 $\mathrm{T}$ ). In other words, EMFTW is more effective than the tap water during the hydration process.

Inside the electromagnetic field generated by electromagnetic device, the magnetic force can fragment small clusters of water; as a result, the efficiency of water is increased [Aarfane et al.2014]. As the hydration of cement grains is increased, the speed of distribution and penetration 

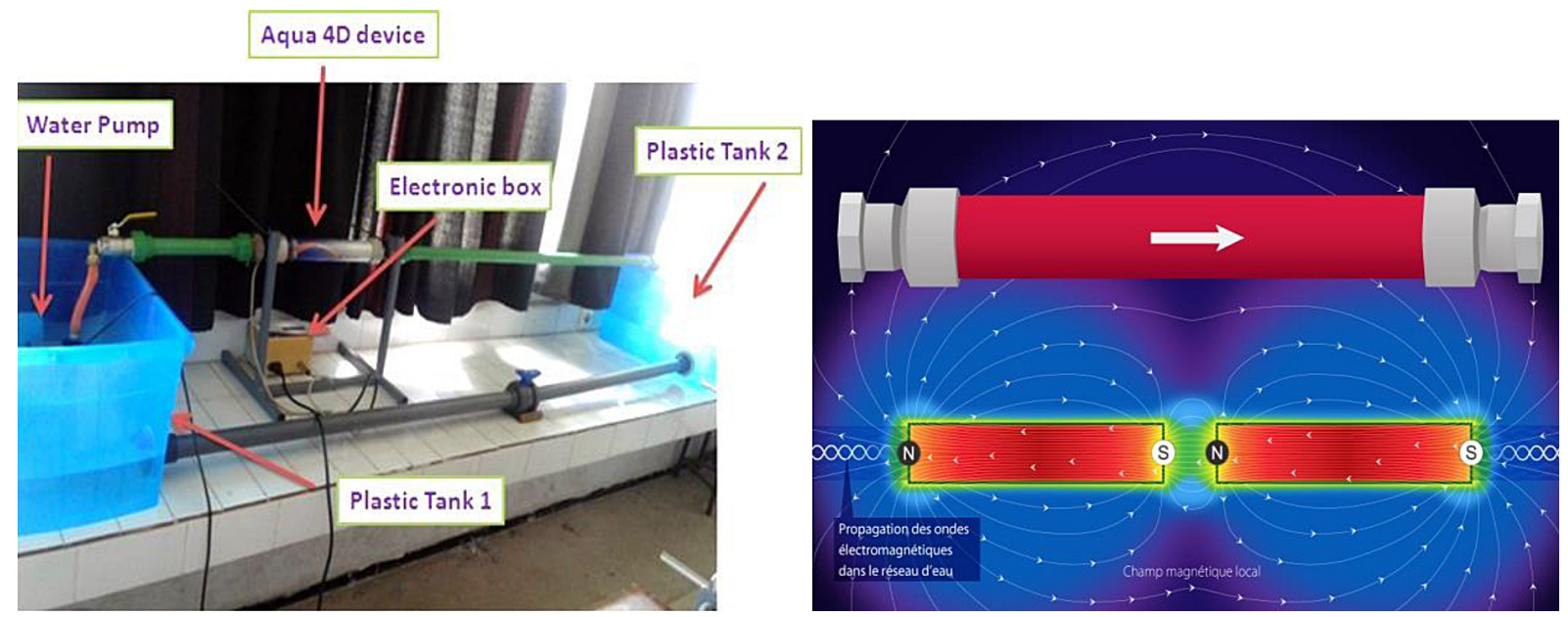

Figure 7. The image of the Aqua 4 D device generating an electromagnetic field

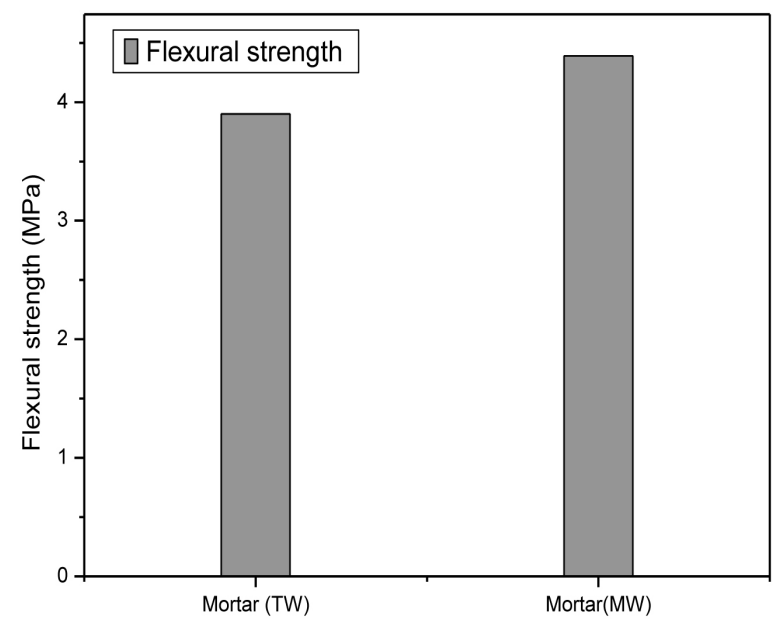

Figure 8. The flexural strength of normal mortar prepared with tap water (TW) and magnetized water (MW)

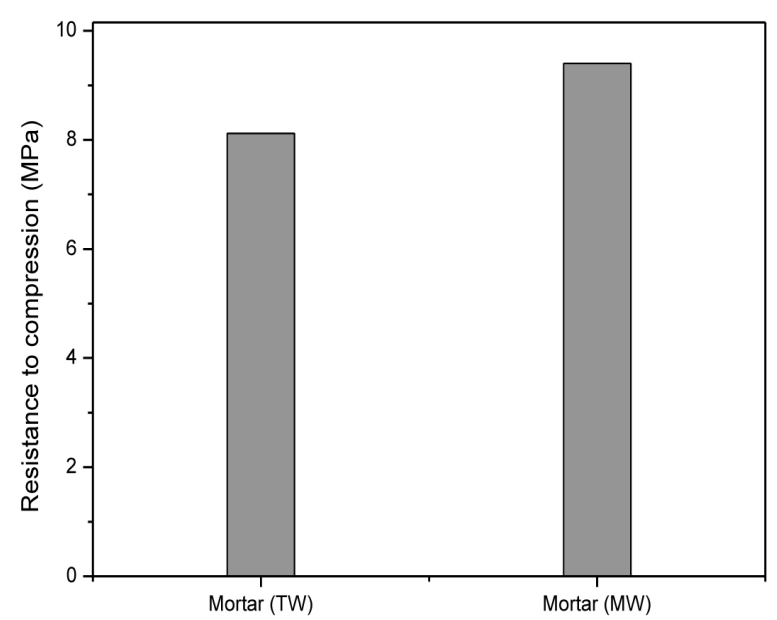

Figure 10. Compressive strength of normal mortar prepared with tap water (TW) and magnetized water (MW)

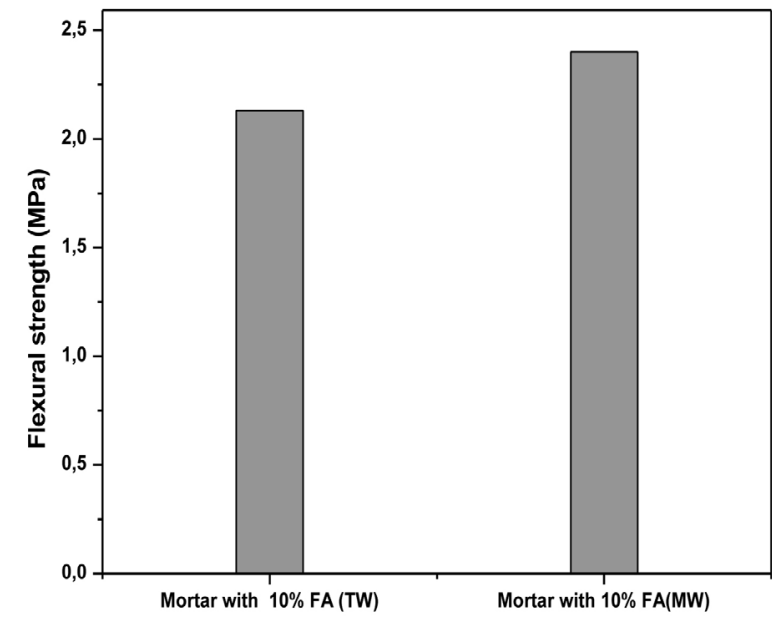

Figure 9. The flexural strength of the mortar prepared with $10 \%$ fly ash (FA) with tap water (TW) and mortar with $10 \%$ fly ash (FA) and magnetized water (MW)

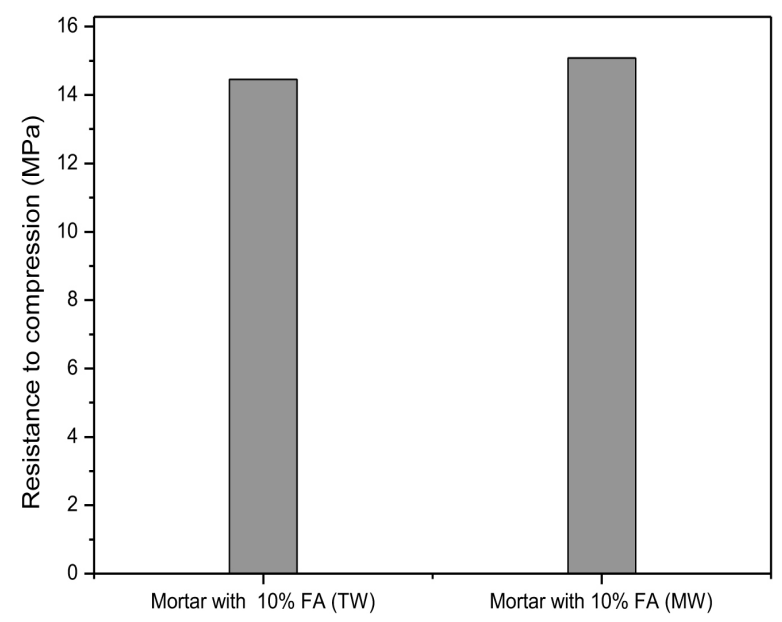

Figure 11. The compressive strength of mortar prepared with $10 \%$ fly ash (FA) with tap water (TW) and mortar with $10 \%$ fly ash (FA) and magnetized water (MW) 
of EMFTW through the almost impermeable layer of cement paste is higher than that of the tap water. As a result, hydration is improved, which increases the strength of the mortar. In addition, during hydration, the clusters of magnetized water become smaller and easily dispersed and penetrated through the cement particles, which improves the reaction of water with cement and the interface of magnetized water with particles of sand and fly ash will increase [Yu et al. 1998]. In addition, the mortar manufactured by EMFTW contains fewer micropores because it is denser and therefore less permeable to water through the mortar [Su et al. 2000].

\section{Characterization of mortars by X-ray spectroscopy}

From the X-ray diffraction diagram in Figure 12 three main phases were identified, which are the calcium carbonate phase $\left(\mathrm{CaCO}_{3}\right)$ which was observed at positions ( 2 theta) $\left(23.01^{\circ} ; 29.37^{\circ}\right.$; $35.98^{\circ}$; $39.41^{\circ}$; $43.14^{\circ}$; $47.28^{\circ}$; $48.49^{\circ}$ ), silicon oxide $\left(\mathrm{SiO}_{2}\right)$ which was revealed at positions (2 theta) $\left(20.79^{\circ} ; 26.60^{\circ} ; 39.41^{\circ} ; 40.17^{\circ} ; 45.83\right.$ ${ }^{\circ} ; 50.04^{\circ} ; 59.93^{\circ} ; 68.07^{\circ}$ ) and finally the iron oxide phase $\left(\mathrm{Fe}_{2} \mathrm{O}_{3}\right)$ at position (2 theta) $\left(18.03^{\circ}\right)$.

From the X-ray diffraction diagram in Figure 13 three main phases were identified which are the calcium carbonate phase $\left(\mathrm{CaCO}_{3}\right)$ which was observed at positions ( 2 theta) $\left(23.04^{\circ} ; 29.41^{\circ}\right.$; $36.02^{\circ} ; 39.44^{\circ} ; 47.45^{\circ} ; 57.42^{\circ}$ ), another phase identified is silicon oxide $\left(\mathrm{SiO}_{2}\right)$ which was revealed at positions ( 2 theta) $\left(20.85^{\circ} ; 26.63^{\circ}\right.$; $50.15^{\circ}$ ); two new phases were also observed in the mortars prepared with (MW) which are the $\mathrm{Mg}_{3}\left(\mathrm{SO}_{4}\right)_{2}(\mathrm{OH})_{2}$ phase at the positions (2 theta) $\left(27.5^{\circ}, 34.1^{\circ}\right)$ and the $\mathrm{Al}_{2} \mathrm{CaO}_{8} \mathrm{SiO}_{4}$ phase at the positions ( 2 theta) $\left(28.04^{\circ}\right)$.

Figures 12 and 13 show that the most marked differences between the four types of mortars consist in the creation of new crystalline phases in the mortars prepared with (MW) which are the phase $\mathrm{Mg}_{3}(\mathrm{SO} 4)_{2}(\mathrm{OH})_{2}$ at positions (2 theta) $\left(27.5^{\circ}\right.$, $\left.34.1^{\circ}\right)$ and the $\mathrm{Al}_{2} \mathrm{CaO}_{8} \mathrm{SiO}_{4}$ phase at positions (2 theta) $\left(28.04^{\circ}\right)$ something which proves the existence of crystallization process on the one hand and the influence of the electromagnetic field strength on the chemical hydration process of cementon the other hand. Figure 12 shows that the most intense peak of RX is that of silicon oxide $\left(\mathrm{SiO}_{2}\right)$ the content of which increased by thirteen times compared to the peak $\left(\mathrm{SiO}_{2}\right)$ of the mortar elaborated by the tap water due to the influence of the electromagnetic field on the preparation water of the mortar which is in agreement with [Yu et al. 1998, An-Tai et al. 2007, Madsen et al. 2004]. Figure 12 also shows that the height of the peak of calcium carbonate $\left(\mathrm{CaCO}_{3}\right)(5.1 \mathrm{cps})$ in the mortar prepared by (MW) is large compared to that of the mortar prepared with (TW) $(4.3 \mathrm{cps})$, which shows that the magnetized water (MW) promotes the crystallization of calcium carbonate. This agrees with the other characterization results presented above concerning the physical, mechanical and microstructural properties. In a previous article, it was concluded that a magnetic field accelerates the crystallization of poorly soluble

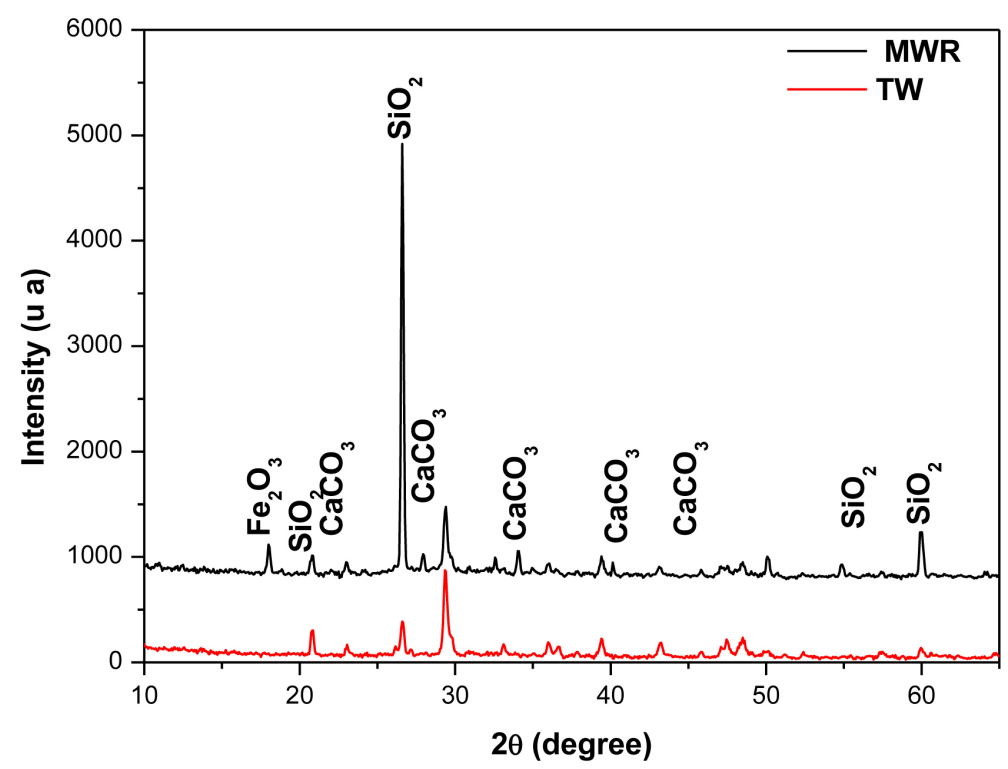

Figure 12. RX diagram of diffraction of mortars with TW and MW 


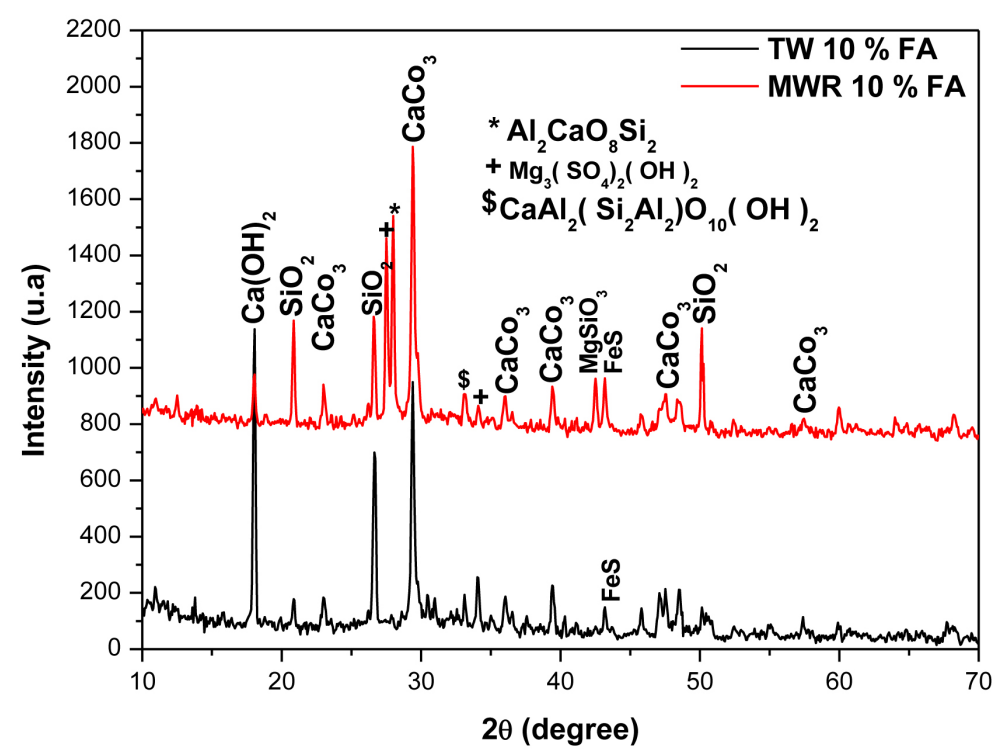

Figure 13. RX diagram of mortar diffraction with TW with FA and MW with FA

diamagnetic salts of weak acids and calcium carbonate [An-Tai et al. 2007, Saddam et al. 2014]. It is also observed in figure 13 that the peak height of the CSH phase of calcium silicate hydrate in the mortar based on (MW) is $17.5 \%$ greater compared to the mortar based on (TW), the CSH phase is the important phase involving the evolution of physical characteristics and more particularly the mechanical characteristics the mortar [Joshi et al. 1966]. Figure 13 shows that the portlandite peak $\mathrm{Ca}(\mathrm{OH})_{2}$ in the fly ash mortar and (TW) is three times higher than the peak of the fly ash mortars and (MW) because the magnetized waterfavors the reaction of the portlandite with the components of the mortar thing which has contributed to the reduction of the intensity of the peak in the mortar based on the magnetized water (MW of) but the contribution this phase on the mechanical strength is weak; on the other hand, portlandite is important in the sustainability mechanism [Joshi et al. 1966].Smaller water molecules of EMFTW reacted with the mortars. This difference explains why the compressive and flexural strength of cementitious materials with EMFTW is higher than that with the tap water [Taylor et al. 1986, Mghaiouini et al. 2020, Borowski al. 2016].

\section{The effects of MFTW on the microstructure of mortars}

In order to visualize the morphologies of the cement matrix and the fly ash in mortars and composites, the SEM photos (Figures 14 and 15) were taken for samples of mortar with or without fly ash. Figures 14 and 15 show the crystals of the cement prepared with tap water and MFTW, respectively. The morphology of the cement in the mortars to be prepared with magnetic water is close to that to be prepared with the tap water. The tap water molecules tend to clump together and form clusters, which could be produced after the cement has reacted with these pooled water molecules (Figure 14 a and Figure 15a). Figures $14 \mathrm{~b}$ and $15 \mathrm{~b}$ show that the cement crystals in the magnetized water-based mortar (MW) tend to be more dispersed than the mortars prepared with the tap water (TW) and form separately, the compressive and bending strength of mortars based on the magnetized water is greater than that with the tap water because the size of the clusters of MFTW is smaller reacted with the cement.

\section{CONCLUSIONS}

The objective of this study was to show the possible uses of MFTW for the improvement of the physicochemical and mechanical characteristics of certain building material and to find the possible processes of the influence of the MFTW on materials. The tests carried out under the effect of the electromagnetic field proved its influence on the physical characteristics linked to the strength of the cement mortar made from fly ash waste.

Regarding the flexural strength of the normal mortar without the addition of fly ash prepared 


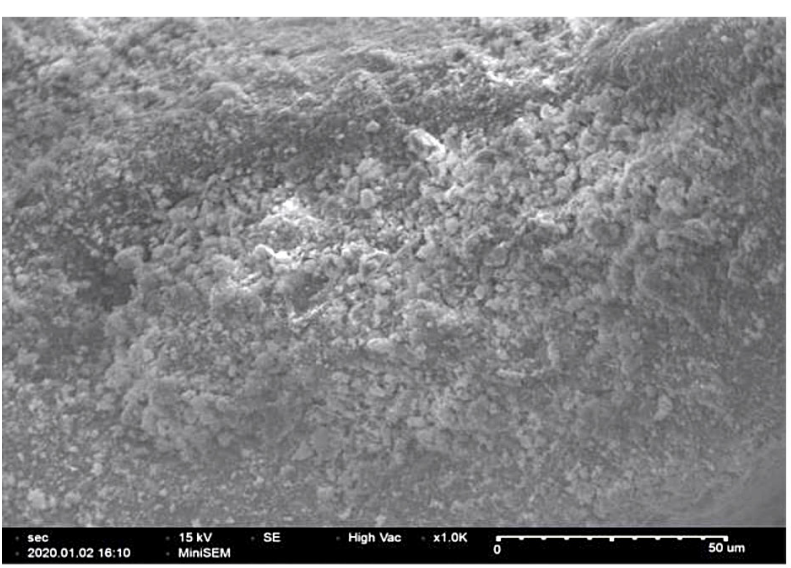

(a)

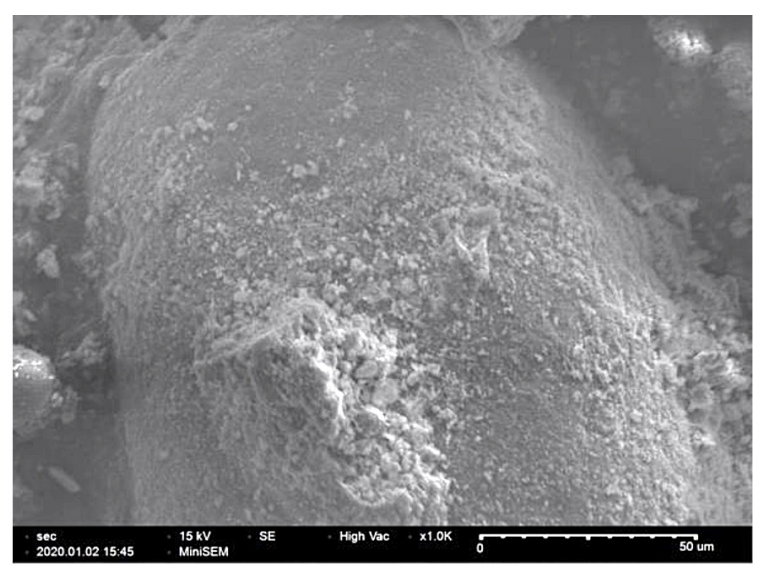

(b)

Figure 14. SEM micrograph of mortar prepared with MW and TW (1000×)

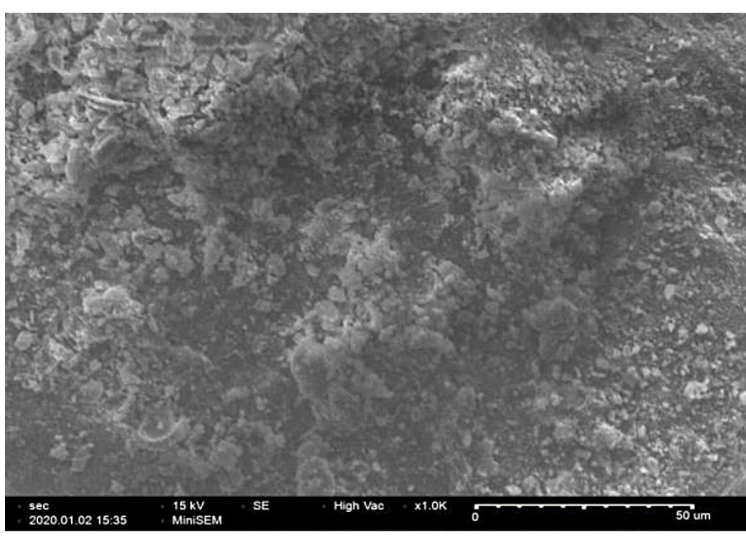

(a)

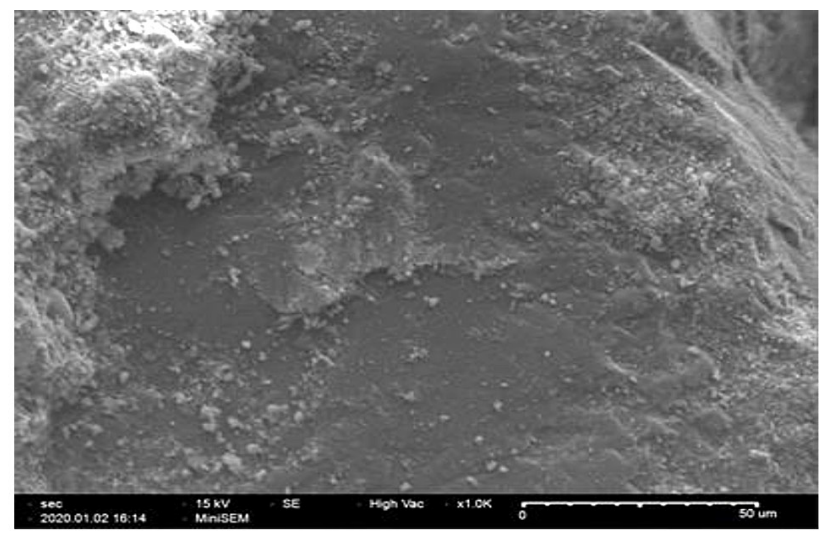

(b)

Figure 15. SEM micrograph of mortar prepared with $10 \%$ of fly ash using MW magnet water and TW tap water $(1000 \times)$

with MFTW, it increased by $12.56 \%$ compared to the mortar prepared with the tap water and for the mortar with prepared with (10\% fly ash-MFTW) the flexural strength was increased by $12.67 \%$ compared to the mortar prepared with $(10 \%$ fly ash - tap water).

Regarding the compressive strength of the normal mortar without the addition of fly ash prepared with MFTW, it increased by $15.8 \%$ compared to the mortar prepared with the tap water and for the mortar with prepared with $(10 \%$ fly ash - MFTW) the compressive strength is increased by $4.35 \%$, compared to the mortar prepared with (10\% fly ash - tap water).

The recovery of waste from the thermal center at the same time prevents the exhaustion of raw materials in nature and takes into account the protection of the environment. It must, of course, be associated with an increased global demand.

\section{REFERENCES}

1. Aarfane A., Salhi A., El Krati M., Tahiri S., Monkade M., Lhadi E.K., Bensitel M. 2014. Kinetic and thermodynamic study of the adsorption of Red195 and Methylene blue dyes on fly ash and bottom ash in aqueous medium. J. Mater. Environ. Sci., 5(6), 1927-1939.

2. Adamiec P., Benezet J.C, Benhassaine A. 2005. Relationship between a silico-aluminous fly ash and its coal. Ecole des Mines d'Alès 6, Avenue de Clavières 30319 ALES Cedex.

3. Afshin H., Gholizadeh M., Khorshidi N. 2010. Improving mechanical properties of high strength concrete by magnetic water technology. Scientia Iranica, Transaction A: Civil Engineering, 17, 74-79.

4. Borowski G. and Hycnar J.J. 2016. The effect of granulated fly ashes with phosphogypsum on the hardening of cement mortar. Technical Transactions - Civil Engineering, 113, 2-B(7), 37-45. 
5. Fan M., Brown R., Wheelock T.D., Cooper A.T., Nomura M., Zhuang Y. 2005. Production of a complex coagulant from fly ash. Chem. Eng. J., 106, 269-277.

6. Graich A., Bellarbi A., Khaidar M., Monkade M., Laamyem A., Rhanim H., Zradba A.2020. Stabilization/solidification by Portland cement of sludge as a residue of filtered waste water from a cardboard plant. Journal of Hazardous, Toxic, and Radioactive Waste, DOI: 10.1061/(ASCE)HZ.2153- 445 5515.0000506.

7. Helmuth R. 1987. Cendres volantes dans le ciment et le béton. Portland Cement Association, Illinois.

8. Joshi K.M. and Kamet P.V.1966. Effect of magnetic field on the physical properties of water. J.Ind. Chem.Soc. 43, 620-622.

9. Ma A-T. 2007. Effect of magnetic water on engineering properties of self -compacting concrete with waste catalyst. A thesis submitted to institue of construction Engineering National Yunlin University of science and Technology in Partail Fulfillment of the Requirement for degree of Master of design in Construction Engineering Taiwan-Republic of China.

10. Madsen H.E.L. 2004. Crystallization of calcium carbonate in magnetic field in ordinary and heavy water. Journal of Crystal Growth, 267(1-2), 251-255.

11. Manjupriya T. and Malathy R. 2016. Experimental investigation on strength and shrinkage properties of concrete mixed with magnetically treated water. International Journal of Engineering and Advanced Research Technology, 2(3), 46-50.

12. Mehta P.K. 1986. Concrete Structure, propriétés et matériaux. Prentice-Hall Inc, falaises d'Englewood (NJ).

13. Mghaiouini R., Elaoud A., Garmim T., Belghiti M.E., Valette E., Faure C.H., Hozayn M., Monkade M., El Bouari A. 2020. The electromagnetic memory of water at kinetic condition. International Journal of Current Engineering and Technology, 11-18, DOI: https://doi.org/10.14741/ijcet/v.10.1.3

14. Mghaiouini R., Graich A., Elaoud A., Garmim T., Belghiti M.E., Benzbiria N., Hozayn M., Monkade M., El Bouari A. 2020. Formulation and physico-mechanical characterization of an eco-mortar composite based on bottom ash and magnetized water. Indian Journal Science and Technology, DOI: $10.17485 / \mathrm{ijst} / 2020 / \mathrm{v} 13 \mathrm{i} 01 / 000000$

15. Mghaiouini R., Elaouad A., Taimourya H., Sabir I., Chibi F., Hozayn M., Garmim T., Nmila R., Rchid H., Monkade M., El Bouari A. 2020. Influence of the electromagnetic device on water quality and germination of lettuce (Lactuca sativa L.). International
Journal of Current Engineering and Technology, 10(1), DOI: 10.14741/ijcet/v.10.1.4.

16. Moufti A. 2003. Doctoral thesis. Faculty of Sciences, Chourai Doukkali University, El Jadida, Morocco.

17. Nan S. and Wu C-F. 2003. Effect of magnetic field treated water on mortar and concrete containing fly ash. Cement \& Concrete Composites, 25, 681-688.

18. Pang X-F. and Zhu X-C. 2013. The magnetization of water arising from a magnetic-field and its applications in concrete industry. International Journal of Engineering Research and Applications, 3(5), 1541-1552.

19. Pradnya U., Rahul D., Abhijeet P. 2016. Wadekar, performance evaluation of magnetic field treated water on convectional concrete containing fly ash. International Journal of Science Technology and Management, 5(2), 68-77.

20. Saddam M. and Ahmed M. 2014. Effect of magnetic water on engineering properties of concrete. AlRafedain Engineering, 17(1), 77-82.

21. Siva Konda Reddy B., Vaishali G., Sudarsana Rao H. 2013. Effect of Magnetic Field Exposure Time on Workability and Compressive Strength of Magnetic Water Concrete. International Journal of Advanced Engineering Technology, 4, 120-122.

22. Soto-Bernal J.J., Gonzalez-Mota R., Rosales-Candelas I., Ortiz-Lozano J.A. 2015. Effects of static magnetic fields on the physical, mechanical, and microstructural properties of cement pastes. Advances in Materials Science and Engineering, http://dx.doi. org/10.1155/2015/934195.

23. Su N., Wu Y., Mar C. 2000. Effect of magnetic water on the engineering properies of concrete containing granulated blast-furnace slage. Cement and Concrete Research, 30(4), 599-605.

24. Taylor H.F.W. 1986. Proposed structure for calcium silicate hydrate Gel. J. Am. Ceram. Soc., 69, 464-467.

25. UN Water Statistics 2014. The United Nations Inter-Agency Mechanism on all Freshwater Related Issues, Including Sanitation (available at: http:// www.unwater.org/statistics/en/).

26. Yu Q., Sugita S., Sawayama K., Soijma Y. 1998. Effect of electronic water hardening and electronic hardening on concrete resistance. Cem. Concret Res., 28, 1201-1208.

27. Zalaghi A., Lamchouri B., Toufik H., Merzoukia M. 2018. Valorization of natural porous materials in the treatment of leachate from the landfill uncontrolled city of Taza. Journal of Materials and Environmental Science, 5(5), 1643-1652. 